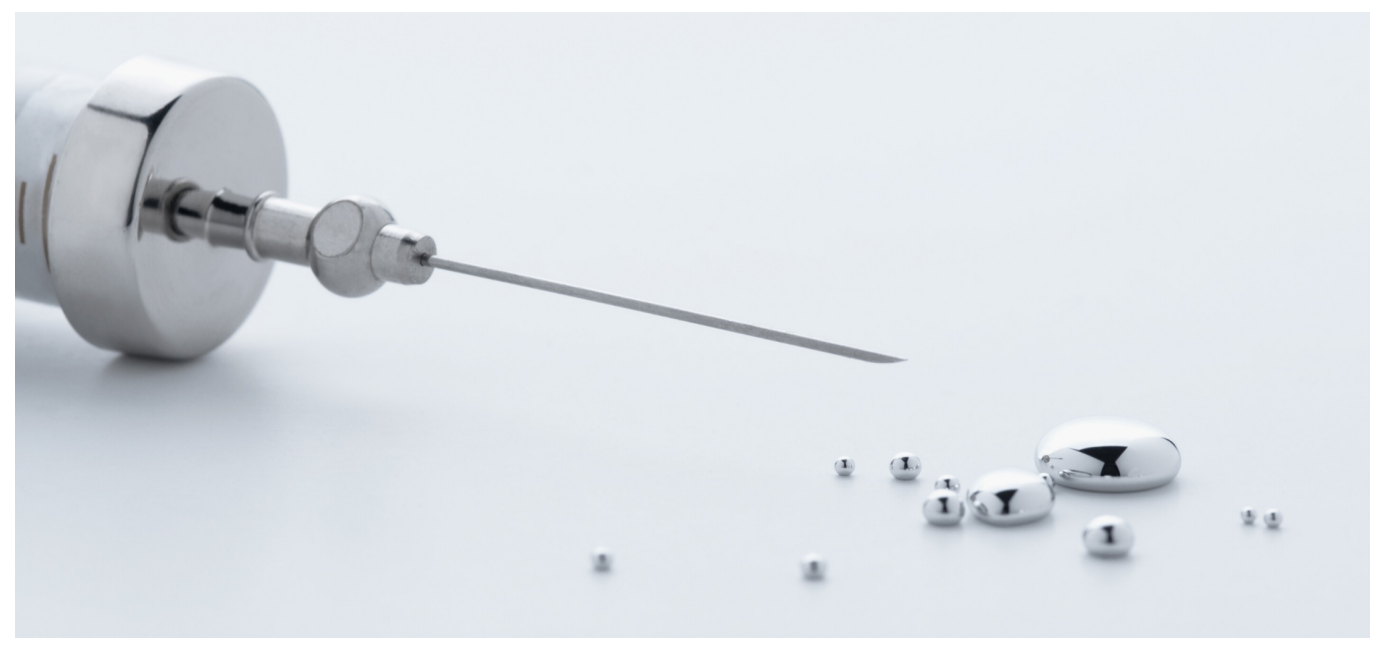

\title{
Mercury as a factor in COVID-19 mortality: hypothesis and evidence.
}

Tim X Lee

Funding: The author(s) received no specific funding for this work.

Potential competing interests: The author(s) declared that no potential competing interests exist.

\section{Abstract}

The majority of those infected with COVID-19 recover without serious complications. However, a small subset of the population is unable to recover from infection and tragically succumb. Conditions found in those that suffer poor COVID19 outcomes are hypercoagulability, high levels of pro-inflammatory cytokines, and lymphopenia. These rare conditions can all be caused by mercury. In addition, men are more likely to die from infection than women. Mercury can account for this gender skew as it is potentiated by testosterone. The hypothesis is that mercury toxicity is causing a susceptibility to COVID-19 death. This hypothesis offers a mechanistic understanding of COVID-19 deaths. Mercury sets the stage by suppressing the immune system and causing hypercoagulability. COVID-19 infection then triggers coagulation leading to thrombosis and an increase in proinflammatory cytokines resulting in patient death.

\section{Introduction}

Coronavirus disease 2019 (COVID-19) is a global pandemic that is currently the focus of an unprecedented wave of research. A characterizing feature of COVID-19 is that the majority of people infected fight it off effectively with few or no symptoms presented. ${ }^{1-5}$ The typical immune response is more than sufficient to overcome the virus. There is however a small section of the population that is not able to do that and tragically succumb. There is something different about this subset of the population. 
Factors that increase one's risk for succumbing to the virus are lymphopenia, high levels of pro-inflammatory cytokines, hypercoagulability, age, being male, hypertension, obesity and diabetes.$^{6-9}$ All of these disparate factors can be attributed to mercury toxicity. Below I review each factor and the evidence that it can be linked to mercury. Then I analyze this evidence to develop a mechanistic model of COVID-19 mortality.

\section{Methodology:}

To identify the known factors that increase one's risk for COVID-19 death and acute respiratory distress syndrome (ARDS), a literature review via Google Scholar and PubMed was used. Each of the identified factors was cross-referenced to determine if heavy metal toxicity could cause the change. Surprisingly, all of the factors can be explained by mercury toxicity. The following is a brief summary of the risk factors and a summary of the role that mercury may play in them.

\section{Results}

Lymphopenia: a below normal number of lymphocytes, has been of interest since the outset of the pandemic. ${ }^{10}$ Tan et al (2020) documented that lymphopenia predicts the severity of COVID-19 disease. ${ }^{7}$ Lymphopenia is associated with COVID-19 death and acute respiratory distress syndrome (ARDS). ${ }^{11}$ Gallais et al (2020) illustrate a mechanism for lymphopenia leading to poor patient outcome because viral-specific T cells are critical in fighting COVID-19 infection. ${ }^{5}$ One would expect those with low T cell counts to fair worse. Mercury causes T cell death. 12,13

Cytokine response: COVID-19 deaths appear to be related to the immune system launching a "cytokine storm" wherein excessive levels of cytokines are released triggering a chain of events that can kill the patient. ${ }^{8}$ Mercury alters the cytokine response by increasing proinflammatory cytokines. Intriguingly, the relationship is even more specific than that; interleukin-1 $\beta$ (IL-1 $\beta$ ), IL-6, IL-8 cytokines are at the heart of COVID-19 induced cytokine storms, these are the exact cytokines that mercury increases. ${ }^{14-17}$

Hypercoagulability: Endemen et al (2020) found that COVID-19 is linked to hypercoagulability. ${ }^{6}$ This conclusion is supported by cohort studies that found hypercoagulability and a severe inflammatory state in COVID-19 patients. ${ }^{18,19}$ Hypercoagulability is one of the known effects of mercury. ${ }^{20-22}$ Viral infections activate the blood coagulation system. ${ }^{23}$ Additionally, coagulation stimulates the cytokine response and the expression of IL-1 $\beta$ genes. ${ }^{24,25}$

Gender skew: Men are more likely to die from COVID-19 infection than women. ${ }^{26,27}$ Although there has been much speculation as to why, currently there is no known mechanism. Mercury offers a mechanism for the gender skew because it affects males and females differently. Males are more sensitive to mercury because it is potentiated by testosterone. ${ }^{28-31}$ The combination of mercury and testosterone should make men more vulnerable to COVID-19 death and therefore skew the deaths toward males.

Age: The risk of COVID-19 related death increases with age. ${ }^{32}$ Seniors have significantly higher mercury levels in their blood than young people because each year you typically retain more than you excrete. ${ }^{33}$

Hypertension: Hypertension is a common COVID-19 comorbidity. $\underline{9}$ Heavy metals increase risk for hypertension. ${ }^{34-38}$ Mercury causes hypertension by inactivating catecholamine-0-methyltransferase, which increases serum and urinary epinephrine, norepinephrine, and dopamine. This effect increases blood pressure. ${ }^{34}$

Selenium deficiency: Selenium deficiency is associated with COVID-19 deaths. ${ }^{39}$ Mercury depletes selenium. ${ }^{40}$

Diabetes: Diabetes is a common comorbidity of COVID-19. ${ }^{9}$ Mercury has a demonstrated link with diabetes. ${ }^{41-44}$

Obesity: Obesity is a common comorbidity of COVID-19. ${ }^{9}$ Mercury has a demonstrated link with obesity. 45 


\section{Discussion}

My hypothesis is that bioaccumulation of mercury is making certain individuals susceptible to COVID-19 mortality. A hypothetical mechanism is illustrated in Figure 1. Mercury induced hypercoagulation is touched off by COVID-19 infection. Coagulation induces proinflammatory cytokine response exacerbated by mercury causing a cytokine storm.

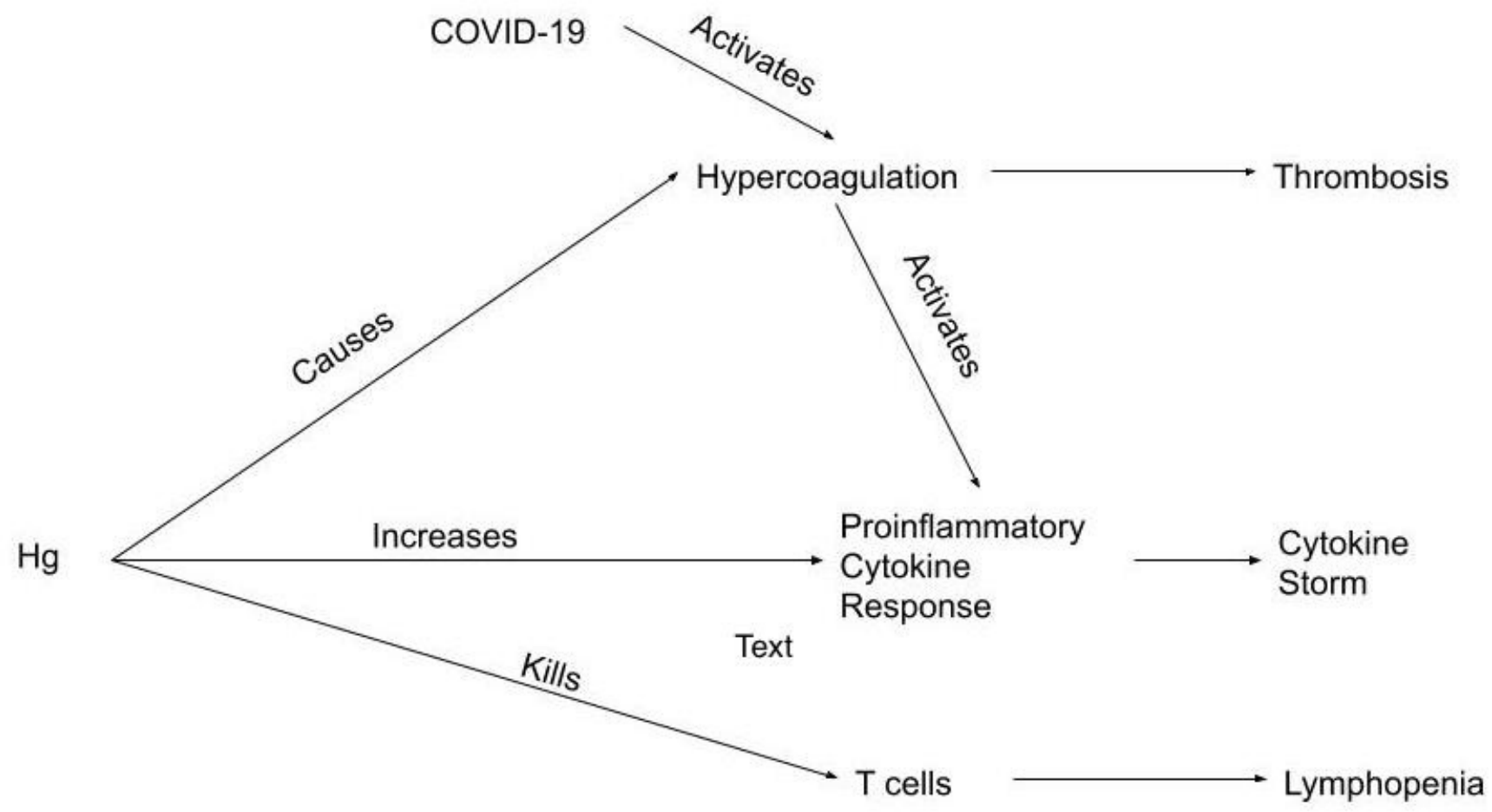

Figure 1. Illustrated is the hypothesized mechanism by which mercury $(\mathrm{Hg})$ toxicity is interacting with COVID-19 to lead to patient mortality. Mercury is known to cause hypercoagulation and a proinflammatory cytokine response. COVID-19 touches off hypercoagulation which activates the proinflammatory cytokine response. Mercury is an immunosuppressant that kills T cells and could account for the observed lymphopenia in patients with poor outcomes.

Mercury has become an ubiquitous toxin in the modern world and each year our exposure to it increases. ${ }^{46}$ We ingest it from seafood, dental amalgams, cosmetics, rice, corn syrup and vaccines. ${ }^{47-53}$ Mercury is released into the biosphere from the burning of fossil fuels, gold mining, food processing and many other sources. As the mercury in the biosphere increases so does the mercury in our food, air and water. The mercury content in tuna is rising at four percent annually. ${ }^{54}$ Six to eight percent of women of childbearing age have a mercury burden that is of concern. That number jumps to fifteen percent when accounting for transplacental mercury transportation. ${ }^{55}$ Since the consumption of mercury containing products varies widely between individuals, the bioaccumulation of mercury also varies widely. In addition, some individuals are poor at excreting mercury once it is in their system. ${ }^{56}$ That means certain individuals have very high levels of mercury relative to the rest of the population. Although mercury is recognized as the most toxic heavy metal, it is usually accompanied by other toxic heavy metals. Arsenic and lead are also infamous for immunosuppresion. ${ }^{57-62}$ This is important because the bioaccumulation of multiple heavy metals potentiates the effect of mercury. ${ }^{63-66}$ As our exposure to these immunosuppressive heavy metals continues to rise we should expect that infections that may have previously been harmless will become more serious. Mercury exposure is already shown to increase the virulence of viral infections. ${ }^{67}$ It 
would be no surprise that a highly contagious coronavirus combined with global mercury contamination would lead to a pandemic.

Coronavirus are frequently innocuous, as is COVID-19 to the majority of people it infects. That opens the possibility that what we are seeing is not a new deadly strain of virus but a virus interacting with an acquired immune disorder. What may be different is not the lethality of the virus but the fact that it is new, highly contagious, spreading rapidly, thereby triggering an avalanche of fatalities amongst those with a heavy metal induced immune disorder.

Science creates falsifiable hypotheses. If mercury is making people susceptible to COVID-19, those with an adverse reaction (e.g. thrombosis and cytokine storm) should have higher levels of mercury than those who do not have an adverse reaction. This is an easily testable and falsifiable hypothesis. Further research should compare heavy metal levels in the two groups. In addition to testing for mercury it should test for substances known to potentiate the effect of mercury such as other heavy metals and testosterone.

If it turns out that mercury is causing a vulnerability to COVID-19 then we have gained an invaluable tool for identifying who is at risk and a method to proactively reduce risk. In addition to saving priceless human life, this discovery could save the world economy tens of trillions of dollars.

\section{Conclusions}

The evidence suggests that mercury toxicity could make COVID-19 patients vulnerable to ARDS and death. Mercury can account for all of the disparate factors that are associated with poor COVID-19 outcomes.

Further research is needed to explore the hypothesis that mercury may be a critical factor in the COVID-19 pandemic.

1. Baggett TP, Keyes H, Sporn N, Gaeta JM. Prevalence of SARS-CoV-2 Infection in Residents of a Large Homeless Shelter in Boston. JAMA. Published online April 27, 2020. doi:10.1001/jama.2020.6887

2. Baggett TP, Keyes H, Sporn N, Gaeta JM. COVID-19 outbreak at a large homeless shelter in Boston: Implications for universal testing. medRxiv. Published online April 15, 2020:2020.04.12.20059618. doi:10.1101/2020.04.12.20059618

3. Day M. Covid-19: four fifths of cases are asymptomatic, China figures indicate. BMJ. 2020;369. doi:10.1136/bmj.m1375

4. Mizumoto K. Kagaya K, Zarebski A. Chowell G. Estimating the asymptomatic proportion of coronavirus disease 2019 (COVID-19) cases on board the Diamond Princess cruise ship, Yokohama, Japan, 2020. Eurosurveillance. 2020;25(10):2000180. doi:10.2807/1560-7917.ES.2020.25.10.2000180

5. Gallais F. Velay A. Wendling M-J, et al. Intrafamilial Exposure to SARS-CoV-2 Induces Cellular Immune Response without Seroconversion. medRxiv. Published online June 22, 2020:2020.06.21.20132449.

doi:10.1101/2020.06.21.20132449

6. Endeman H, Zee P van der, Genderen ME van, Akker JPC van den, Gommers D. Progressive respiratory failure in COVID-19: a hypothesis. Lancet Infect Dis. 2020;0(0). doi:10.1016/S1473-3099(20)30366-2

7. Tan L, Wang Q, Zhang D, et al. Lymphopenia predicts disease severity of COVID-19: a descriptive and predictive study. Signal Transduct Target Ther. 2020;5(1):1-3. doi:10.1038/s41392-020-0148-4

8. Jose RJ, Manuel A. COVID-19 cytokine storm: the interplay between inflammation and coagulation. Lancet Respir Med. 2020;0(0). doi:10.1016/S2213-2600(20)30216-2

9. Richardson S, Hirsch JS, Narasimhan M, et al. Presenting Characteristics, Comorbidities, and Outcomes Among 5700 
Patients Hospitalized With COVID-19 in the New York City Area. JAMA. Published online April 22, 2020. doi:10.1001/jama.2020.6775

10. Huang C, Wang Y, Li X, et al. Clinical features of patients infected with 2019 novel coronavirus in Wuhan, China. The Lancet. 2020;395(10223):497-506. doi:10.1016/S0140-6736(20)30183-5

11. Huang I, Pranata R. Lymphopenia in severe coronavirus disease-2019 (COVID-19): systematic review and metaanalysis. J Intensive Care. 2020;8(1):36. doi:10.1186/s40560-020-00453-4

12. Guo TL, Miller MA, Shapiro IM, Shenker BJ. Mercuric chloride induces apoptosis in human T lymphocytes: evidence of mitochondrial dysfunction. Toxicol Appl Pharmacol. 1998;153(2):250-257. doi:10.1006/taap.1998.8549

13. Shenker BJ, Guo TL, O I. Shapiro IM. Induction of apoptosis in human T-cells by methyl mercury: temporal relationship between mitochondrial dysfunction and loss of reductive reserve. Toxicol Appl Pharmacol. 1999;157(1):23-35. doi:10.1006/taap.1999.8652

14. Gardner RM, Nyland JF, Evans SL, et al. Mercury Induces an Unopposed Inflammatory Response in Human Peripheral Blood Mononuclear Cells in Vitro. Environ Health Perspect. 2009;117(12):1932-1938. doi:10.1289/ehp.0900855

15. Lubick N. IMMUNITY: Mercury Alters Immune System Response in Artisanal Gold Miners. Environ Health Perspect. 2010;118(6):A243.

16. Silva IA, Nyland JF, Gorman A, et al. Mercury exposure, malaria, and serum antinuclear/antinucleolar antibodies in amazon populations in Brazil: a cross-sectional study. Environ Health. 2004:3:11. doi:10.1186/1476-069X-3-11

17. Yamamoto M, Khan N, Muniroh M, et al. Activation of interleukin-6 and -8 expressions by methylmercury in human U937 macrophages involves RelA and p50. J Appl Toxicol. 2017;37(5):611-620. doi:10.1002/jat.3411

18. Panigada M, Bottino N, Tagliabue P, et al. Hypercoagulability of COVID-19 patients in Intensive Care Unit. A Report of Thromboelastography Findings and other Parameters of Hemostasis. J Thromb Haemost JTH. Published online April 17. 2020. doi:10.1111/jth. 14850

19. Spiezia L, Boscolo A, Poletto F, et al. COVID-19-Related Severe Hypercoagulability in Patients Admitted to Intensive Care Unit for Acute Respiratory Failure. Thromb Haemost. Published online April 21, 2020. doi:10.1055/s-0040-1710018 20. Worowski K. The Hypercoagulability in Mercury Chloride Intoxicated Dogs. Thromb Haemost. 1968;19(1/2):236-241. doi:10.1055/s-0038-1651201

21. Lim K-M, Kim S, Noh J-Y, et al. Low-Level Mercury Can Enhance Procoagulant Activity of Erythrocytes: A New Contributing Factor for Mercury-Related Thrombotic Disease. Environ Health Perspect. 2010;118(7):928-935. doi:10.1289/ehp.0901473

22. Song Y. [Effects of chronic mercury poisoning on blood coagulation and fibrinolysis systems]. Zhonghua Lao Dong Wei Sheng Zhi Ye Bing Za Zhi Zhonghua Laodong Weisheng Zhiyebing Zazhi Chin J Ind Hyg Occup Dis. 2005;23(6):405-407. 23. Antoniak S. The coagulation system in host defense. Res Pract Thromb Haemost. 2018:2(3):549-557. doi:10.1002/rth2.12109

24. Mileno MD, Margolis NH, Clark BD, Dinarello CA, Burke JF, Gelfand JA. Coagulation of whole blood stimulates interleukin-1 beta gene expression. J Infect Dis. 1995;172(1):308-311. doi:10.1093/infdis/172.1.308 25. Poll T van der, Jonge E de, An H ten C. Cytokines as Regulators of Coagulation. Landes Bioscience; 2013. Accessed 
June 7, 2020. https://www.ncbi.nlm.nih.gov/books/NBK6207/

26. Jin J-M, Bai P, He W, et al. Gender Differences in Patients With COVID-19: Focus on Severity and Mortality. Front Public Health. 2020;8. doi:10.3389/fpubh.2020.00152

27. Ford RVR and T. COVID-19 much more fatal for men, especially taking age into account. Brookings. Published May 15, 2020. Accessed August 29, 2020. https://www.brookings.edu/blog/up-front/2020/05/15/covid-19-much-more-fatal-formen-especially-taking-age-into-account/

28. Mckeown-Eyssen GE, Ruedy J, Neims A. METHYL MERCURY EXPOSURE IN NORTHERN QUEBEC: II. NEUROLOGIC FINDINGS IN CHILDREN. Am J Epidemiol. 1983;118(4):470-479. doi:10.1093/oxfordjournals.aje.a113652 29. Clarkson T. Nordberg G. Sager P. Reproductive and Developmental Toxicity of Metals. Scand J Work Environ Health. 1985:11:145-154. doi:10.5271/sjweh.2239

30. Geier MR, Geier DA. The potential importance of steroids in the treatment of autistic spectrum disorders and other disorders involving mercury toxicity. Med Hypotheses. 2005;64(5):946-954. doi:10.1016/..mehy.2004.11.018

31. Mutter J, Naumann J, Schneider R, Walach H, Haley B. Mercury and autism: accelerating evidence? Neuro Endocrinol Lett. 2005;26(5):439-446.

32. Zhou F, Yu T, Du R, et al. Clinical course and risk factors for mortality of adult inpatients with COVID-19 in Wuhan. China: a retrospective cohort study. The Lancet. 2020;395(10229):1054-1062. doi:10.1016/S0140-6736(20)30566-3 33. Government of Canada SC. Lead, mercury and cadmium concentrations in Canadians, 2012 and 2013. Published July 15, 2015. Accessed April 30, 2020. https://www150.statcan.gc.ca/n1/pub/82-625-x/2015001/article/14209-eng.htm 34. Houston MC. Role of Mercury Toxicity in Hypertension, Cardiovascular Disease, and Stroke. J Clin Hypertens. 2011:13(8):621-627. doi:10.1111/j.1751-7176.2011.00489.x

35. Jaishankar M, Tseten T, Anbalagan N, Mathew BB, Beeregowda KN. Toxicity, mechanism and health effects of some heavy metals. Interdiscip Toxicol. 2014;7(2):60-72. doi:10.2478/intox-2014-0009

36. Alghasham AA, Meki A-RMA, Ismail HAS. Association of Blood Lead level with Elevated Blood Pressure in Hypertensive Patients. Int J Health Sci. 2011:5(1):17-27.

37. Hu XF. Singh K. Chan HM. Mercury Exposure. Blood Pressure, and Hypertension: A Systematic Review and Doseresponse Meta-analysis. Environ Health Perspect. 2018:126(7). doi:10.1289/EHP2863

38. Sørensen N, Murata K, Budtz-Jørgensen E, Weihe P, Grandjean P. Prenatal Methylmercury Exposure as a Cardiovascular Risk Factor at Seven Years of Age. Epidemiology. 1999:10(4):370-375.

39. Moghaddam A, Heller RA, Sun Q, et al. Selenium Deficiency Is Associated with Mortality Risk from COVID-19. Nutrients. 2020;12(7). doi:10.3390/nu12072098

40. Spiller HA. Rethinking mercury: the role of selenium in the pathophysiology of mercury toxicity. Clin Toxicol Phila Pa. 2018:56(5):313-326. doi:10.1080/15563650.2017.1400555

41. Kolachi NF, Kazi TG, Afridi HI, et al. Status of toxic metals in biological samples of diabetic mothers and their neonates. Biol Trace Elem Res. 2011:143(1):196-212. doi:10.1007/s12011-010-8879-7

42. Tsai T-L, Kuo C-C, Pan W-H, Wu T-N, Lin P. Wang S-L. Type 2 diabetes occurrence and mercury exposure - From the National Nutrition and Health Survey in Taiwan. Environ Int. 2019:126:260-267. doi:10.1016/j.envint.2019.02.038 43. Higher mercury levels in humans associated with increased risk for diabetes. ScienceDaily. Accessed April 30, 2020. 
https://www.sciencedaily.com/releases/2013/04/130407211547.htm

44. He K, Xun P, Liu K, Morris S, Reis J, Guallar E. Mercury exposure in young adulthood and incidence of diabetes later in life: the CARDIA Trace Element Study. Diabetes Care. 2013;36(6):1584-1589. doi:10.2337/dc12-1842

45. Wang X, Mukherjee B, Park SK. Associations of cumulative exposure to heavy metal mixtures with obesity and its comorbidities among U.S. adults in NHANES 2003-2014. Environ Int. 2018;121(Pt 1):683-694.

doi:10.1016/j.envint.2018.09.035

46. Siblerud R, Mutter J, Moore E, Naumann J, Walach H. A Hypothesis and Evidence That Mercury May be an Etiological Factor in Alzheimer's Disease. Int J Environ Res Public Health. 2019;16(24). doi:10.3390/ijerph16245152

47. Xun P. Liu K. Morris JS. Jordan JM. He K. Distributions and determinants of mercury concentrations in toenails among American young adults: the CARDIA Trace Element Study. Environ Sci Pollut Res Int. 2013;20(3):1423-1430. doi:10.1007/s11356-012-1126-3

48. Parkin Kullmann JA, Pamphlett R. A Comparison of Mercury Exposure from Seafood Consumption and Dental Amalgam Fillings in People with and without Amyotrophic Lateral Sclerosis (ALS): An International Online Case-Control Study. Int J Environ Res Public Health. 2018:15(12). doi:10.3390/ijerph15122874

49. McKelvey W, Alex B, Chernov C, et al. Tracking Declines in Mercury Exposure in the New York City Adult Population, 2004-2014. J Urban Health Bull N Y Acad Med. 2018;95(6):813-825. doi:10.1007/s11524-018-0269-z

50. Bulka CM, Davis MA, Karagas MR, Ahsan H, Argos M. The Unintended Consequences of a Gluten-free Diet. Epidemiology. 2017:28(3):e24. doi:10.1097/EDE.0000000000000640

51. Woods JS, Martin MD, Leroux BG, et al. The Contribution of Dental Amalgam to Urinary Mercury Excretion in Children. Environ Health Perspect. 2007:115(10):1527-1531. doi:10.1289/ehp.10249

52. Gallagher CM, Goodman MS. Hepatitis B vaccination of male neonates and autism diagnosis, NHIS 1997-2002. J Toxicol Environ Health A. 2010;73(24):1665-1677. doi:10.1080/15287394.2010.519317

53. Geier DA, Kern JK, Homme KG, Geier MR. A Cross-Sectional Study of the Association between Infant Hepatitis B Vaccine Exposure in Boys and the Risk of Adverse Effects as Measured by Receipt of Special Education Services. Int $J$ Environ Res Public Health. 2018:15(1). doi:10.3390/ijerph15010123

54. Drevnick PE, Lamborg CH, Horgan MJ. Increase in mercury in Pacific yellowfin tuna. Environ Toxicol Chem. 2015;34(4):931-934. doi:10.1002/etc.2883

55. Mahaffey KR. Mercury Exposure: Medical and Public Health Issues. Trans Am Clin Climatol Assoc. 2005:116:127-154. 56. Sandborgh-Englund G, Elinder C-G, Johanson G, Lind B, Skare I, Ekstrand J. The Absorption, Blood Levels, and Excretion of Mercury after a Single Dose of Mercury Vapor in Humans. Toxicol Appl Pharmacol. 1998:150(1):146-153. doi:10.1006/taap.1998.8400

57. Mishra KP, Rani R, Yadav VS, Naik S. Effect of lead exposure on lymphocyte subsets and activation markers. Immunopharmacol Immunotoxicol. 2010;32(3):446-449. doi:10.3109/08923970903503668

58. Soto-Peña GA, Luna AL, Acosta-Saavedra L, et al. Assessment of lymphocyte subpopulations and cytokine secretion in children exposed to arsenic. FASEB J. 2006;20(6):779-781. doi:10.1096/fj.05-4860fje

59. Vianna A dos S, Matos EP de, Jesus IM de, et al. Human exposure to mercury and its hematological effects: a systematic review. Cad Saúde Pública. 2019;35(2). doi:10.1590/0102-311×00091618 
60. Oulhote Y, Shamim Z, Kielsen K, et al. Children's white blood cell counts in relation to developmental exposures to methylmercury and persistent organic pollutants. Reprod Toxicol. 2016;68. doi:10.1016/j.reprotox.2016.08.001

61. Gonsebatt ME, Vega L, Herrera LA, et al. Inorganic arsenic effects on human lymphocyte stimulation and proliferation. Mutat Res. 1992:283(2):91-95. doi:10.1016/0165-7992(92)90139-9

62. Burchiel SW, Lauer FT, Beswick EJ, et al. Differential susceptibility of human peripheral blood T cells to suppression by environmental levels of sodium arsenite and monomethylarsonous acid. PloS One. 2014:9(10):e109192. doi:10.1371/journal.pone.0109192

63. Kenston SSF, Su H, Li Z, et al. The systemic toxicity of heavy metal mixtures in rats. Toxicol Res. 2018;7(3):396-407. doi:10.1039/C7TX00260B

64. Alexandrov PN, Pogue Al, Lukiw WJ. Synergism in aluminum and mercury neurotoxicity. Integr Food Nutr Metab. 2018:5(3). doi:10.15761/IFNM.1000214

65. Saghazadeh A, Rezaei N. Systematic review and meta-analysis links autism and toxic metals and highlights the impact of country development status: Higher blood and erythrocyte levels for mercury and lead, and higher hair antimony, cadmium, lead, and mercury. Prog Neuropsychopharmacol Biol Psychiatry. 2017;79(Pt B):340-368.

doi:10.1016/j.pnpbp.2017.07.011

66. Haley BE. Mercury toxicity: genetic susceptibility and synergistic effects. Med Veritas J Med Truth. 2005:2:535-542. doi:10.1588/medver.2005.02.00070

67. Cooper LT, Rader V, Ralston NVC. The Roles of Selenium and Mercury in the Pathogenesis of Viral Cardiomyopathy. Congest Heart Fail. 2007:13(4):193-199. doi:10.1111/j.1527-5299.2007.06410.x 